\title{
РОЗШИРЕННЯ ОПЕРАЦЙ АЛГЕБРИ ПОКАЗНИКІВ ДЛЯ УПРАВЛІННЯ СИСТЕМАМИ 3 НЕПОВНІСТЮ ВИЗНАЧЕНИМИ ПОКАЗНИКАМИ ДІЯЛЬНОСТІ
}

\begin{abstract}
Анотація: Розглядається розширення операцій реляційної алгебри показників для управління системами 3 неповністю визначеними показниками діяльності стосовно випадку інтервального н-розширення.

Ключові слова: показники діяльності, алгебра показників, недовизначені моделі.
\end{abstract}

\section{Вступ}

Управління організаційно-виробничою системою (OBC) із застосуванням економіко-математичних методів і моделей має на меті постійне підвищення ефективності їі діяльності, яку характеризуе ряд показників діяльності. Саме у термінах таких показників предметні спеціалісти та менеджери формулюють як цілі так і критерії їх досягнення. Цілі кожного рівня дерева цілей фрунцціонування ОВС являють собою виконання задач ефективного управління (оптимізації, регулювання, тощо) по певним показникам.

Універсальна множина показників системи управління (та відповідно системи прийняття рішень що до цілепокладання та вибору покращуючих втручань на кожній фразі діяльності) утворюе іерархічні структури (“ліс") із слабкими зв'язками. На кожному рівні іерархії можливі не повністю узгоджені бачення експертів різної спеціалізації щодо критеріїв та обмежень значень показників діяльності та їх переліку. Типовими також е ситуації фіксації неповних знань про значення показників у вигляді певних множин, які достеменно містять невизначене точно на поточний момент значення.

Звертаючись до досліджень формулювання знань про конкретні предметні області (ПО) у вигляді взаємопов'язаних показників діяльності, скористаємося роботою [1], в якій надано математичний апарат що до операцій з показниками, та [2], що містить методи інтерпретації операцій з показниками та їх перетворень, безпосередньо у базу даних.

\section{Постановка задачі}

Як самі показники так і системоутворюючі зв'язки достатньо зручно моделюються багатомісними відношеннями. Властивості зв'язків, вимірювані в числових шкалах зручно моделювати показниками. Тоді синергетичні властивості формулюються у вигляді виразів алгебри показників (ВАП), що важливо для автоматизації підготовки програмних продуктів маніпулювання та збереження структур показників [1].

(c) О.В. Гриша, 2012 
Формулювання вимог до діяльності бізнесу у вигляді денотатів певних характеристик показників у більшості випадків не задовольняе потреби реального життя, оскільки знання, що “витягують” з експертів, як правило містять різні види так званих “не-факторів" [3], у зв'язку з чим нотації моделей опису знань повинні забезпечувати можливість фіксації і обробки не повністю (частково) відомої інформації. Для реальної системи знань характерні такі властивості, як недовизначеність, неточність, неповнота, некоректність, нечіткість та ін. У даній роботі надається найбільша увага недовизначеності. Недовизначеність - властивість даних і знань, визначена як часткове знання про сутність (показник) $x$, обмежене інформацією про те, що $x$ належить до деякої конкретної множини $X$. Уточнення даних про $x$ приводить до зменшення потужності множини $X$, що в потенціалі стягуеться до одного елементу, який відображає повну інформацію про $x$. Н-моделі були запропоновані на початку 80-х років для подання і обробки не повністю визначених знань [3]. Н-модель є набором обмежень $R=\left\{R_{1}, R_{2}, \ldots R_{k}\right\}$ над змінними $x_{1}$, $x_{2}, \ldots x_{n}$ з областями значень відповідно $A_{1}, A_{2}, \ldots, A_{n}$. Обмеження можуть мати вид рівнянь, нерівностей, логічних виразів і тому подібне.

Таким чином актуальною $е$ постановка задачі розширення можливостей опису знань ПО з допомогою показників додаванням операцій н-розширення, яке включає як відповідний тип н-змінної, так і відповідне розширення операцій (н-операції) і відношень (н-відношення) початкової формальної системи.

\section{Н-розширення операцій над показниками}

Алгебра показників, як і ї̈ н-розширення є відгалуженням логіки першого порядку і розглядаеться як множина показників замкнених операторами реляційної алгебри та додатковими операторами алгебри показників.

Показником $P$ над $H_{i}, A_{k_{1}}, \ldots, A_{k_{n}}$ називатимемо будь-яку множина кортежів відношень, для яких виконуеться фрункціональна залежність

$$
A_{k_{1}}, \ldots, A_{k_{n}} \rightarrow H_{i},
$$

де $\left\{A_{i}\right\}, i=\overline{1, n}$ - множина імен об'ектів предметної області. 3 кожним елементом $A_{i}$ пов'язано множину екземплярів $D O M\left(A_{i}\right)$. Під об'єктом розуміеться частина атрибутів з певними властивостями, серед яких слід виділити такі: має дискретну множину значень; існуе хоч одна функціональна залежність до лівої частини якої він входить; вступае у відношення з іншими об'єктами; позначає предмети, дії, інтервали часу.

$\left\{H_{j}\right\}, j=\overline{1, k}$ - множина імен характеристик предметної області. При цьому

$$
\left\{A_{i}\right\} \cap\left\{H_{j}\right\}=\emptyset .
$$

З кожним Нј зв'язано множину значень характеристики, $D O M\left(H_{j}\right) \in$ $R$, де $R$ - множина чисел. Характеристики це інший різновид атрибутів, 
який має такі особливості: позначає властивість предмета чи відношення предметів; не вступае в відношення з іншими характеристиками; не фігуруе в лівих частинах функціональних залежностей і тому не може бути первинним атрибутом; обов'язково фігуруе в правих частинах функціональних залежностей.

Схемою показника називається сукупність імен з множини $\left\{A_{i}\right\}, i=$ $\overline{1, n}$. Схема може включати деякі імена більше одного разу, тобто схема є деякий комплект імен.

Для позначення схеми, характеристики, основи і сімейства показника $P$ вводяться [1] $S H(P), C H(P), F M(P), R(P)$ - відповідно, "об'ектної"частини кортежу " $k$ що визначається на об'єктах і що позначаеться $R\left(P_{i}, k\right)$ і "характеристичної"частини, що визначається на характеристиці і позначаеться $H\left(P_{i}, k\right)$. При цьому:

$$
k \in R(P i, k) \cup H(P i, k) .
$$

Кортежем показника над $H_{i}, A_{k_{1}}, \ldots, A_{k_{n}}$ називається відображення

$$
<H_{i}, A_{k_{1}}, \ldots, A_{k_{n}}>\rightarrow \operatorname{DOM}\left(H_{i}\right) \times \operatorname{DOM}\left(A_{k_{1}}\right) \times \ldots \times \operatorname{DOM}\left(A_{k_{n}}\right) .
$$

Візьмемо визначення можливих розширень для показників аналогічно [3].

1) Н-розширення, в якому кожен його елемент представлений точним значенням * $X=X^{\text {single }}$

$$
X^{\text {single }}=\{\{x\} \mid x \in X\} \cup\{\emptyset\} \cup\{X\} \ldots
$$

Дане н-розширення додає в звичайний універсум два спеціальні значення: не визначена $(X)$ і суперечність $(\emptyset)$.

2) Н-розширення перерахування представляеться множиною всіх підмножин (яке позначимо $2^{X}$ ):

$$
X^{\text {enum }}=2^{X} .
$$

Дане н-розширення можна застосовувати лише до кінцевих універсумів.

У разі, коли $X$ e решіткою (множиною з визначеними на ній асоціативними і комутативними операціями, що підкоряються законам поглинання і ідемпотентності), можна задати такі види н-розширень $X$, як інтервали і мультиінтервали .

3) Інтервальне н-розширення:

$$
X^{\text {Interval }}=\left\{\left[x^{L o}, x^{U p}\right] \mid x^{L o}, x^{U p} \in X\right\} .
$$

Тут $x^{L o}$ позначає нижню, а $x^{U p}-$ верхню границю інтервалу. Пуста множина $\emptyset)$ представляеться будь-яким інтервалом $\left[x^{L o}, x^{U p}\right]$, де $x^{L o}>$ $x^{U p}$.

4) Мультиінтервальне н-розширення:

$$
X^{\text {MultiInterval }}=\left\{x \mid x=x_{k}, x_{k} \in X^{\text {Interval }}\right\} .
$$




\section{Властивості недовизначених розширень}

Хай як н-розширення безлічі чисел розглядається н-розширення Interval, а відповідні н-розширення операцій мінус (*-) і плюс $\left(*_{+}\right)$визначені згідно відомим правилам інтервальної арифметики [3]. Таким чином, Н-розширення унарного мінуса має вигляд

$$
\text { *- : }\left[P_{1}^{L o}, P_{2}^{U p}\right]=\left[-P_{1}^{U p}, P_{2}^{L o}\right] ;
$$

а н-розширення додавання також виконуеться за умови, що $S H\left(P_{1}\right)=$ $S H\left(P_{2}\right)$,

і обчислюеться таким чином:

$$
\begin{gathered}
P_{3}=P_{1} * \oplus P_{2} \Leftrightarrow R\left(P_{3}\right)=R\left(P_{1}\right) \cup R\left(P_{2}\right) \\
\left(\forall k \in R\left(P_{3}\right)\right) \\
H\left(P_{3}, k\right)=\left\{H\left(P_{1}, k\right)^{L o}, H\left(P_{1}, k\right)^{U p}, \text { якщо } k \in R\left(P_{1}\right) \backslash R\left(P_{2}\right),\right. \\
H\left(P_{1}, k\right)^{L o}+H\left(P_{2}, k\right)^{L o}, H\left(P_{1}, k\right)^{U p}+H\left(P_{2}, k\right)^{U p}, \\
\text { якщо } k \in R\left(P_{1}\right) \text { та } k \in R\left(P_{2}\right), \\
\left.H\left(P_{2}, k\right)^{L o}, H\left(P_{2}, k\right)^{U p} \text { в іншому випадку }\right\} .
\end{gathered}
$$

За відсутності характеристик $* \oplus$ виконуеться, як $U$ тобто як звичайна операція реляційної алгебри.

Віднімання визначається як похідна операція (формула )

$$
P_{3}=P_{1} * \oplus P_{2}=P_{1} * \oplus\left(*-P_{2}\right)
$$

У такому разі, Н-розширення виразу (1) має наступний вигляд:

$$
\begin{aligned}
& P_{3}=\left[P_{1}^{L o}, P_{1}^{U p}\right] * \oplus\left(\left[P_{2}^{L o}, P_{2}^{U p}\right]\right)=\left[P_{1}^{L o}, P_{1}^{U p}\right] * \oplus\left(\left[-P_{2}^{U p},-P_{2}^{L o}\right]=\right. \\
& =\left[P_{1}^{L o}+\left(-P_{2}^{U p}\right], P_{1}^{U p}+\left(-P_{2}^{L o}\right)\right]=\left[P_{1}^{L o}-P_{2}^{U p}, P_{1}^{U p}-P_{2}^{L o}\right] .
\end{aligned}
$$

Достатньо очевидно, що коли нижня і верхня межі н-числа не співпадають (тобто число недовизначене), інтервал $\left[P_{1}^{L o}-P_{2}^{U p}, P_{1}^{U p}-P_{2}^{L o}\right]$ всього лише містить нульовий елемент, але не рівний в точності йому.

Операції ділення та множення показників розширюються наступним чином.

Розширення для інтервального множення:

$$
\begin{gathered}
P_{3}=P_{1} * \otimes P_{2} \Leftrightarrow R\left(P_{3}\right)=R\left(P_{1}\right) \triangleright \triangleleft R\left(P_{2}\right) \\
\left(\forall k \in R\left(P_{3}\right)\right)
\end{gathered}
$$




$$
\begin{aligned}
& H\left(P_{3}, k\right)=\min \left\{\left(H\left(\pi S H\left(P_{2}\right)\left(P_{1}\right), k\right)\right)^{L o} \otimes\left(H\left(\pi S H\left(P_{1}\right)\left(P_{2}\right), k\right)\right)^{L o},\right. \\
& \left(H\left(\pi S H\left(P_{2}\right)\left(P_{1}\right), k\right)^{L o}\right) \otimes\left(H\left(\pi S H\left(P_{1}\right)\left(P_{2}\right), k\right)\right)^{U p}, \\
& \left(H\left(\pi S H\left(P_{2}\right)\left(P_{1}\right), k\right)^{U p}\right) \otimes\left(H\left(\pi S H\left(P_{1}\right)\left(P_{2}\right), k\right)\right)^{L o}, \\
& \left.\left(H\left(\pi S H\left(P_{2}\right)\left(P_{1}\right), k\right)\right)^{U p} \otimes\left(H\left(\pi S H\left(P_{1}\right)\left(P_{2}\right), k\right)\right)^{U p}\right\}, \\
& \max \left\{\left(H\left(\pi S H\left(P_{2}\right)\left(P_{1}\right), k\right)\right)^{L o} \otimes\left(H\left(\pi S H\left(P_{1}\right)\left(P_{2}\right), k\right)\right)^{L o},\right. \\
& \left(H\left(\pi S H\left(P_{2}\right)\left(P_{1}\right), k\right)\right)^{L o} \otimes\left(H\left(\pi S H\left(P_{1}\right)\left(P_{2}\right), k\right)\right)^{U p}, \\
& \left(H\left(\pi S H\left(P_{2}\right)\left(P_{1}\right), k\right)\right)^{U p} \otimes\left(H\left(\pi S H\left(P_{1}\right)\left(P_{2}\right), k\right)\right)^{L o}, \\
& \left.\left(H\left(\pi S H\left(P_{2}\right)\left(P_{1}\right), k\right)\right)^{U p} \otimes\left(H\left(\pi S H\left(P_{1}\right)\left(P_{2}\right), k\right)\right)^{U p}\right\} .
\end{aligned}
$$

Операція ділення визначається як множення на обернену величину (формула). Ї̈̈ розширення має вигляд:

$$
P_{3}=P_{1} * / P_{2} \Leftrightarrow P_{3}=P_{1} * \otimes\left(1 / P_{2}\right)
$$

$$
\left(\forall k \in R\left(P_{3}\right)\right)
$$

$$
\begin{aligned}
& H\left(P_{3}, k\right)=\min \left\{\left(H\left(\pi S H\left(P_{2}\right)\left(P_{1}\right), k\right)\right)^{L o} \otimes\left(H\left(\pi S H\left(P_{1}\right)\left(P_{2}\right), k\right)\right)^{L o},\right. \\
& \left(H\left(\pi S H\left(P_{2}\right)\left(P_{1}\right), k\right)\right)^{L o} \backslash\left(H\left(\pi S H\left(P_{1}\right)\left(P_{2}\right), k\right)\right)^{U p}, \\
& \left(H\left(\pi S H\left(P_{2}\right)\left(P_{1}\right), k\right)\right)^{U p} \backslash\left(H\left(\pi S H\left(P_{1}\right)\left(P_{2}\right), k\right)\right)^{L o}, \\
& \left.\left(H\left(\pi S H\left(P_{2}\right)\left(P_{1}\right), k\right)\right)^{U p} \backslash\left(H\left(\pi S H\left(P_{1}\right)\left(P_{2}\right), k\right)\right)^{U p}\right\}, \\
& \max \left\{\left(H\left(\pi S H\left(P_{2}\right)\left(P_{1}\right), k\right)\right)^{L o} \backslash\left(H\left(\pi S H\left(P_{1}\right)\left(P_{2}\right), k\right)\right)^{L o},\right. \\
& \left(H\left(\pi S H\left(P_{2}\right)\left(P_{1}\right), k\right)\right)^{L o} \backslash\left(H\left(\pi S H\left(P_{1}\right)\left(P_{2}\right), k\right)\right)^{U p}, \\
& \left(H\left(\pi S H\left(P_{2}\right)\left(P_{1}\right), k\right)\right)^{U p} \backslash\left(H\left(\pi S H\left(P_{1}\right)\left(P_{2}\right), k\right)\right)^{L o}, \\
& \left.\left(H\left(\pi S H\left(P_{2}\right)\left(P_{1}\right), k\right)\right)^{U p} \backslash\left(H\left(\pi S H\left(P_{1}\right)\left(P_{2}\right), k\right)\right)^{U p}\right\} .
\end{aligned}
$$

Зміна властивості унарного мінуса приводить до того, що закон дистрибутивності для звичайних аддитивних і мультиплікативних операцій переходить в так званий закон субдистрибутивності:

$$
* P_{3} * \otimes\left(* P_{1} * \oplus P_{2}\right) \subseteq * P_{3} * \otimes * P_{1} * \oplus * P_{3} * \otimes * P_{2}
$$

Це підкреслює, що і для показників в н-моделях істотно те, в якому вигляді представлені умови завдання: які н-расширения вибрані для характеристик показників і яким чином представлені обмеження (рівняння і нерівності).

Гібридні формульні операції виду

$$
P=P_{1} \triangleright f^{\mathrm{a}} \triangleleft P_{2},
$$

деव $\in\{+,-, /, *\}$ - арифметична компонента,

$\triangleright f \triangleleft-$ реляційна компонента,

$f$ - умова з'єднання визначаються відповідно базовим визначенням арифмметичних компонент відповідно до визначень [1] та базових розширених операцій.

Як для алгебри показників так і для їі розширення при відповідному визначенні F, гібридна операція покриває операції, задані вище на основі природного з'єднання. За відсутності характеристики в схемі одного 
з аргументів їі значення приймаються рівними одиниці. За відсутності характеристик в схемах обох операндів операція виконуеться як з'еднання умовою.

\section{Висновки}

Оскільки реальний показник завжди має початкові оцінки меж його значень в самому формулюванні знань про ОВС і в процесі вирішення вони додатково уточнюеться, то значення реальних показників завжди частково відомі. Вони знаходиться десь між не визначено і повністю визначено, що в загальному випадку означає, що вони недовизначені. Недовизначене значення $є$ оцінкою величини показника, яка в загальному випадку є за своєю природою точнішою, ніж дозволяе встановити доступна нам в даний момент інформація. Тому моделі ОВС у нотації показників, як будь-якій формальній системі можна зіставити ії недовизначене розширення, яке включає як відповідний тип н-показника, так і відповідне н-розширення операцій відносно початкової системи операцій над показниками[1].

\section{Література}

1. Гриша С.М., Родічева О.С., Прилипко Д.І. Технологічно інтелектуалізовані інформаційні системи для управління бізнесом.

2. Гриша С.Н. Построение текста SQL запроса из реляционного дерева запроса / Гриша С.Н., Родичева О.С., Роздольский Е.О. // Системные технологи - Днепропетровск, 2009. - № 2(61). - с. 42-52. ISSN 15629945.

3. Нариньяни А. С. Недоопределённость в системах представления и обработки знаний //Изв. АН СССР. Техн.кибернетика. 1986. №5.

Отримано 30.11.2012 p. 